\section{RHEOLOGY IN THE TEXTILE INDUSTRIES}

$\mathrm{T}$ HE British Rheologists' Club in association with some provincial branches of the Chemical Society, the Royal Institute of Chemistry, the Society of Chemical Industry and the Institute of Physics, together with the Textile Institute and the Society of Dyers and Colourists, recently organised a twoday discussion (March 19 and 20) on the rheological properties of textile materials. The meetings took place in the Department of Textile Industries of the University of Leeds under the chairmanship of Prof. J. B. Speakman, head of the Department and president of the Rheologists' Club. About a hundred and fifty scientific workers, including a number of overseas visitors, were present, and the problems discussed embraced such diverse phenomena as the flow of fibres over one another in the manufacture of yarns, and the state of orientation of long-chain molecules in viscose rayons.

The first day's proceedings commenced with a paper by D. R. Cox (Wool Industries Research Association) on "Fibre Movement in the Drafting Process". He derived the equations governing the velocity and distribution of the fibres in terms of general expressions for the frictional coefficient of the inter-fibre area of contact, which would depend on the pressure perpendicular to this surface. Only the relatively simple form of the equations was dealt with in the special case of short fibres. He then showed that the initial irregularity of the sliver, characterized by the values of its 'spectra', would be modified by the drafting process so that the spectrum of the issuing sliver could be derived from it by use of the fundamental equations. A single irregularity in the entering sliver was seen to give rise to an emerging wave of irregularities. R. Meredith (British Cotton Industry Research Association) read a paper on "Relaxation and Flow in Cellulose Fibres". The Tobolsky-Eyring-Halsey theory of viscous flow in high polymers was expounded and shown to provide a molecular picture of the delayed elasticity and creep properties of cotton and other such textile fibres. From these phenomena the theory enabled one to calculate the molecular dimensions of the 'flow unit' and the activation energy of the flow process.

Prof. W. E. Morton and F. Permanyer (Manchester College of Technology) then concluded the first session with a paper entitled "Torsional Relaxation in Textile Filaments". The behaviour of a wide range of textile materials had been studied and the data obtained were presented in graphical form. The logarithmic plots of the relaxation of stress with time illustrated the applicability of the NuttingScott Blair equations with only a few exceptions.

On the second day, H. J. Woods, R. R. Mukherjee and M. K. Sen (Textile Physics Department, University of Leeds) presented a short paper on "Some Tensile Properties of Jute". Results were given which emphasized the dependence of the values obtained for Young's modulus and tensile strength on the dimensions of the sample chosen. A significant negative correlation, for example, was shown to exist between the Young's modulus and the denier of the fibre (a measure of the thickness), which is in agreement with the 'weak spot' theory. Relaxation in jute fibres was negligible under the experimental conditions. The next paper, by L. Peters and Prof.
J. B. Speakman (Textile Industries Department, University of Leeds), on "The Viscous-Elastic Properties of Wool Fibres", proposed a new theory of the elastic properties of wool or other keratin fibres. Unlike the kinetic theories of the elasticity of rubber and related high polymers, where extension is regarded as the transition from a disordered to a more ordered state, the new theory makes use of the X-ray data which indicate that keratin is trans. formed from one crystalline state to another by unfolding of the main peptide chains. Assuming that these two forms are in dynamic equilibrium with one another, it follows that there must be some of the extended form present even in unstretched fibres. The load-extension curve of wool in formic acid indicates that this is by no means a negligible proportion of the total. Quantitative analysis of the curve was attempted, and estimates of the change in heat content and entropy of stretching have been evaluated. The creep properties are considered to be due to the transference of stress from the 'crystalline' to the 'amorphous' phase.

This was followed by a paper on "Stress-Strain Characteristics of Viscose Rayon in Relation to Anisotropy" by L. Rose and J. D. Griffiths (Messrs. Courtaulds, Ltd.). The outstanding feature of the work is the discovery of a linear relation between the birefringence and the logarithm of the slope of the load-extension curve of the wet rayon. This enables the birefringence of a specimen to be calculated with an accuracy of 0.001 from a simple measurement of wet tenacity and elongation when the axial swelling is known. It was shown that normal 'unstretched' rayons are anisotropic because of the profound contraction which takes place during drying on the bobbin. Under conditions where free contraction takes place, the material is optically isotropic and the properties of the filaments are in satisfactory agreement with the above linear relation.

The final paper was given by F. S. Warburton (Wool Industries Research Association) on "The Mechanical Properties of Horn". He described optical methcds of determining the elastic constants of strips of horn with high precision at different humidities.

The papers, and the highly interesting discussions which followed, are to be published in the Journal. of the Textile Institute.

L. Peters

\section{RECENT RESEARCH IN MARINE BIOLOGY}

$T$ HE first number of the twenty-seventh volume of the Journal of the Marine Biological Associa. tion contains eight papers on varied aspects of marine biology.

Mr. G. M. Spooner and Dr. Segerstråle describe, in independent papers, their investigations on species of Gammarus, as the result of which we now have a clear picture of the species and varieties of these important marine scavengers. Mr. Spooner's pre-war studies on the quantitative and qualitative distribution in estuaries of $G$. locusta, zaddachi, duebeni, chevreuxi and pulex have been expanded, and linked with the valuable systematic work of Mrs. Sexton. He also had access to the collections of eight zoologists working on different parts of the British and Danish coasts. He distinguishes between the typical forms 